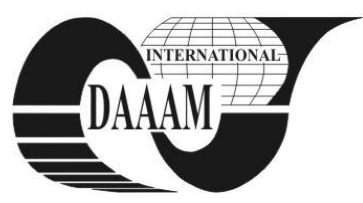

\title{
A SUSTAINABLE MANUFACTURING NETWORK MODEL FOR SOCIO-ECONOMIC DEVELOPMENT
}

\author{
BUTALA, P[eter] \& OOSTHUIZEN, G[ert]
}

\begin{abstract}
South Africa is facing severe poverty levels especially in underdeveloped rural regions. Manufacturing is seen as the sector which could create jobs, but it requires an innovative development concept. The concept of sustainable manufacturing networks is proposed. It is based on the principles of social networks, network manufacturing and open source in order to ensure socio-economic development. An adequate model is created, which relies on a network of selfsustainable autonomous work units interconnected in a network. A learning work unit is particularized. Reconfigurable manufacturing systems and open source ecology equipment are discussed as potential product of a pilot sustainable manufacturing network.
\end{abstract}

Key words: sustainable development, networking, socioeconomy, learning work system

\section{INTRODUCTION}

Manufacturing of products and goods is probably the most important economic activity in the world. It contributes to the quality of life of individuals, to growth of wealth in a nation as well as power and position of a state. Therefore, manufacturing deserves strong and continuous endeavour of all actors in a modern society to ensure prosperity, better life and sustainable development.

Africa is often characterized as the 'silent' continent, because its abundance of knowledge, research and practice does not reach far beyond its local audience. Despite the fact that South Africa (SA) is the most developed country in Africa, there are still rural regions suffering from severe poverty. Few in SA doubt the essential need to grow the manufacturing sector of the country. Still, there is a shortage of new concepts which would fast-track the development of the manufacturing sector, can create new productive jobs and contribute socioeconomically to the country. Globally, we see this shift to a more socially responsible system. More companies realize that it is critical to have a socio-economic strategy and to take responsibility for the regions of the world in which they operate. The ability of independent value co-creation (even in socially- and geographically isolated regions), together with improved teaching capabilities can open numerous possibilities for developing countries. This contribution proposes an innovative concept of sustainable manufacturing networks, which is based on principles of networking with open source software in order to find a faster way to alleviate poverty in SA.

\section{SUSTAINABLE MANUFACTURING}

In order to formulate a new manufacturing model based on sustainability, the governing principles have to be introduced first.

A successful socio-economic (SE) development framework will ensure that the country's geographic area is utilised effectively, the country's people are healthy and educated, the infrastructure is sufficient, and that there are abundant employment opportunities within respected governance systems. Real economic value is created out of these new principles simply due to mass collaboration where people are living, experiencing and expressing gradually more within digitally enabled social- and peer networks. Value within the SE gains real tangible economic expression as it interacts with existing economic systems. Successful SE organisations can play an important role in modern society.

When using the term 'social network' (SN), we do not only refer to friendship or other non-economic linkages, but relate to economic ties that involve ongoing interaction and adjustments, which cannot be reduced to price-based exchanges. Such networks maybe associated with mutual commitment, reciprocity and professional trust. SN enables networking of humans through technology who can now combine their knowledge and creativity in order to create new social norms on wealth creation and social development. SN theory relies on the premise that personal and social networking relationships and ties provide value to organizations in a network by allowing them to tap into the resources embedded within the network for their benefit (Ettlinger, 2003).

In today's highly competitive industrial environment, no individual can accomplish production engineering tasks alone. Collaboration is necessary at every technical and organizational level (Lu et al., 2007). Manufacturing networks (MN) open new possibilities for collaboration in design, development and production. They provide a basis for competitiveness, innovation, agility, reconfigurability and adaptiveness. MNs enable interconnected partners to form long-term business coalitions, develop mutual understanding and trust, jointly react to business opportunities, gain synergetic effects and share information, knowledge, resources and risks.

Most software producers consider source code as valuable intellectual property and make it unavailable. The concept of open source software (OSS) is different. OSS programs (e.g. Linux) give any interested party access to the source code, leading to a distributed innovation platform in which users actively participate in the product's development thus enabling co-creation of value (Ueda et al., 2009). Often free, OSS products are distributed under many public licenses, are more reliable, and provide greater flexibility and choice. The system leads to fascinating competitive and cooperative relationships among companies and communities. Recently, there are initiatives to provide also open source hardware (e.g. Open Source Ecology). The idea here is to provide license free product documentation to be downloaded for a do-it-yourself realization.

\section{A SUSTAINABLE MANUFACTURING NETWORK MODEL}

A networked manufacturing system is a structure, composed of interconnected autonomous building blocks which communicate, cooperate, collaborate and compete among each other. They may also communicate with the environment. 


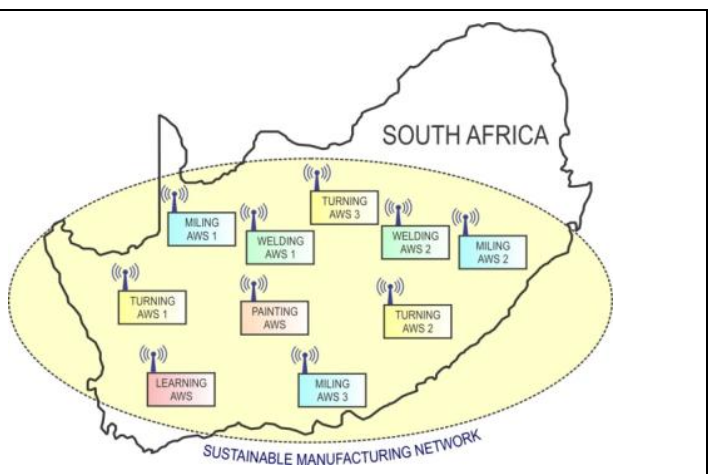

Fig. 1. Model of a sustainable manufacturing network

For designing the building blocks the concept of Autonomous Work Systems (AWS) is proposed in (Butala \& Sluga, 2006). AWS is defined as a rather simple structure with rounded technological functionality and corresponding management functionality. The technological functionality is build around the so called elementary work systems, which are composed of a process (e.g. turning), a device (e.g. a lathe) and a human subject (e.g. machine operator). The management functionality encompasses management and control of work operations and communication and interaction with other systems. From the legal perspective AWS could be a micro enterprise. On this basis, AWS with different technological functionalities competencies, such as, turning, welding, painting, etc., can be designed and implemented.

When designing AWS for rural SA regions one has to have in mind that infrastructure is poor - often no electricity nor water neither broadband connection are available. Therefore, in order for an AWS to operate as a learning factory, the solution should comprise all elements which make it self-sufficient and self-sustainable. The factory-in-a-box concept is proposed here. AWS can be implemented in a container with a build-in electric generator. The container can also be relocated to another location, which provides a mobility dimension to the concept.

Communication and networking technologies are another issue to be solved in this context. The mobile technologies present exciting and new opportunities to those who have not been able to access digital information before. The mobile technology is broadly spread and used by South Africans for browsing the Internet on their mobile phones. The mobile phone is strategic to sustained information on the move in Africa.

By interconnecting several AWSs, a manufacturing network can be established as shown in Fig. 1.

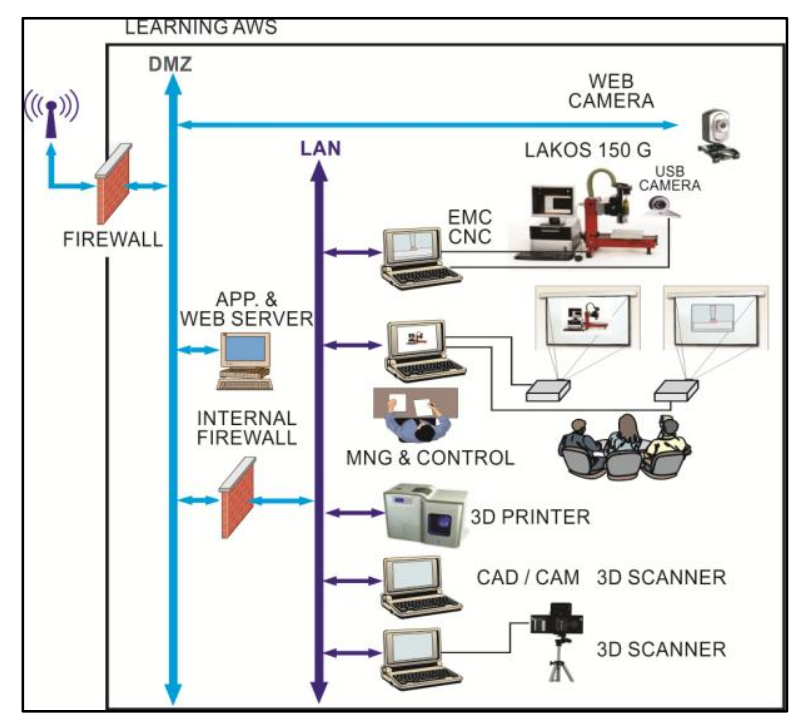

Fig. 2. Learning autonomous work system

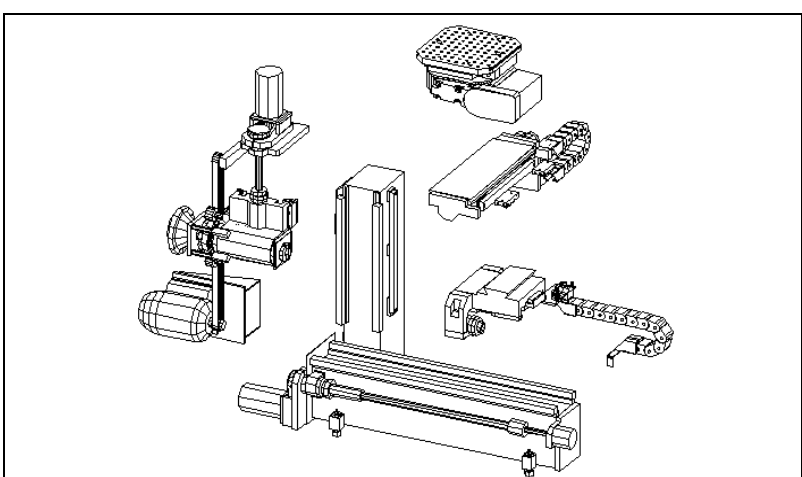

Fig. 3. Reconfigurable machining system LAKOS 250

As an illustrative example a learning AWS is presented in Fig. 2. Due to the lack of manufacturing knowledge, skills and experience, learning is of key to successful implementation of the sustainable manufacturing network concept. Up to date manufacturing, information and communication technologies are foreseen which enable on-site training and distance learning.

In order to assure sustainability, a program of products to be manufactured within the network has to be developed. For a start a pallet of modules for reconfigurable machining systems LAKOS 250 (Fig. 3) is proposed (Peklenik et al., 1994). These machines can form the basic technology of AWSs. Future work can include the integration of open source hardware initiatives and learning material of occupational universities, e.g. Merseta $(* * *, 2011)$

\section{CONCLUSION}

The contribution introduces the innovative concept of sustainable manufacturing networks. Such networks are a viable solution for undeveloped regions. They provide self sufficient autonomous working units interconnected in a social and technological network and operating in accordance to the socio-economic principles. For a pilot implementation, manufacturing of modules for reconfigurable machine tools is proposed. Future work will include engineering of solutions for a pilot implementation and development of learning materials.

\section{ACKNOWLEGEMENT}

The work is the result of a cooperative research performed during the first author's visit at the second author's institution. This work was partially supported by the Ministry of Higher Education, Science and Technology of the Republic of Slovenia, Grant No. L2-2001.

\section{REFERENCES}

Butala, P. \& Sluga, A. (2006), Autonomous Work Systems in Manufacturing Networks. CIRP Ann. Vol. 55/1 pp. 521-524

Ettlinger, N. (2003). Cultural economic geography and a relational and microspace approach to trusts, rationalities, networks, and change in collaborative workplaces. Journal of Economic Geography, Vol. 3, pp. 145-172

Lu, S.C-Y., Elmaraghy, W., Schuh, G., Wilhelm, R. (2007). A scientific foundation of collaborative engineering, CIRP Ann. Vol. 56/2, pp. 606-634

Peklenik J., Klanjšček M., Konjajev A., Logar B., Perme, T., Sluga A., Vengust I., Bervar G. (1994). Development of a Lean Small Scale Flexible Manufacturing System (LFMS) Integrating CAD/CAPP/CAM/CAQ. Manufacturing Systems, Vol. 23/4 4, pp. 335-341

Ueda, K., Takenaka, T., Vancza, J., Monostori, L. (2009). Value creation and decision-making in sustainable society, CIRP Ann., Vol. 58/2, pp. 681-700 